\title{
Effect of Colour Vision on Age Related Macular Degeneration
}

\section{Partha Haradhan Chowdhury ${ }^{1 *}$ and Brinda Haren Shah ${ }^{2}$}

1M.Optom, Associate Professor, Principal, Department of Optometry, Shree Satchandi Jankalyan Samiti Netra Prasikshan Sansthan, Pauri, Affiliated to Uttarakhand State Medical Faculty, Dehradun, India

2M.Optom, Guest Lecturer, Department of Optometry, Shree Satchandi Jankalyan

\section{Research Article}

Volume 3 Special Issue 2

Received Date: September 28, 2018

Published Date: November 02, 2018

DOI: $10.23880 /$ oajo-16000S2-022

Samiti Netra Prasikshan Sansthan, Pauri, Affiliated to Uttarakhand, State Medical Faculty, Dehradun, India

*Corresponding author: Partha Haradhan Chowdhury, M. Optom, Associate Professor, Principal, Department of Optometry, Shree Satchandi Jankalyan Samiti Netra Prasikshan Sansthan, Pauri, Affiliated to Uttarakhand State Medical Faculty, Dehradun, India, Email: optometrypublish@gmail.com

\section{Abstract}

Purpose: Aim of the present study is to evaluate the color vision in subjects of Age Related Macular Degeneration Methods: A pilot, cross sectional, observational study was performed at tertiary eye care centers. Subjects with Age Related Macular Degeneration and age group of 40 to 65 were included in the study. Ocular as well as systemic pathology were excluded. Colour Vision was assessed with Farnsworth D 15 colour vision test.

Results: 83 subjects were included in the study. Out of that 57\% were males and 43\% were females. Mean colour vision was considered for statistical analysis. It shows that Contrast Sensitivity is deteriorated to 1.5 in cases of Age Related Macular Degeneration.

Conclusions: Mild to Moderate Tritanopia occurs in Age Related Macular Degeneration.

Keywords: Colour vision; Age Related Macular Degeneration

\section{Introduction}

ARMD is an age related and usually bilateral condition of the eye. Usually it is the most important reason of blindness. In presence of ARMD, new blood vessels are present under the macular area. Colloid bodies (druses) are also present under the macular area. So, central vision will be lost. Cone cell density is present more in the foveal area compared to para foveal region. Cone cells are solely responsible for colour vision also. So, there are chances of deterioration of colour vision in cases of ARMD [1,2].

\section{Methodology}

A pilot, cross sectional and observational study was performed in tertiary eye care centers in the period of 1 year. All the subjects are enrolled with informed consent. Subjects having Age Related Macular Degeneration are included in the study. Age group of 40 to 65 years was 
included in the study. Subjects having any other ocular pathology including retinal pathology except Age Related Macular Degeneration were excluded from the study. Subjects with systemic disorders were also excluded. Full refractive correction along with Slit lamp examination and detailed fundus evaluation was performed in each and every patient. Colour Vision was assessed with Farnsworth D 15 colour vision test. Data analysis was performed with SPSS software 20 and Microsoft Office Excel 10 [3].

\section{Results}

A total of 83 subjects were included in the study. Figure 1 shows age wise distribution of the subjects. Figure 2 shows gender distribution. Out of 83 subjects, 47 subjects were male and 36 subjects were female. Mean colour vision of 83 subjects were considered for statistical analysis. Figure 3 shows effect on colour vision in age related macular degeneration subjects.

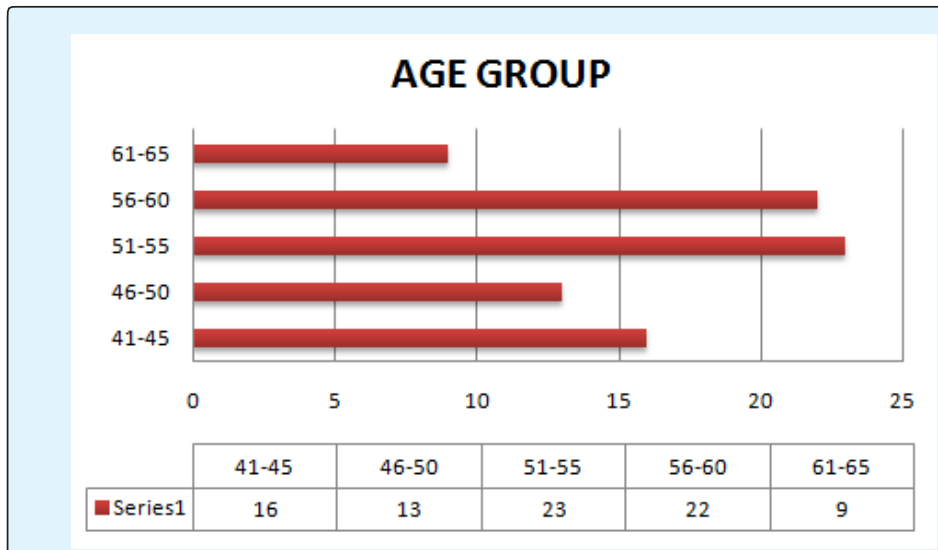

Figure 1: Shows Age wise Distribution of Subjects.

\section{GENDER}

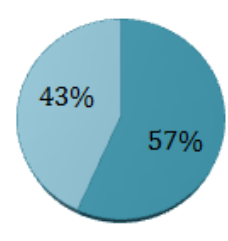

$\square$ MALES

Figure 2: Shows Gender wise Distribution of Subjects.

\section{COLOUR VISION}

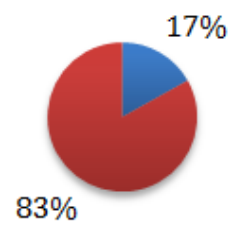

- NORMAL

Figure 3: Shows Effect Of Colour Vision In Age Related Macular Degeneration.

\section{Discussion}

In cases of Age Related Macular Degeneration, there are chances of deterioration of colour vision. In presence of Age Related Macular Degeneration, colloid bodies are present at the macular and foveal area. Central acuity is affected due to the involvement of foveal area. Cone cell density is highest at the foveal area so, definitely cone cells will be damaged. In the present study, in presence of Age Related Macular Degeneration, Tritanopia is present due to more blue cone cells are affected [4].

\section{Conclusions}

Mild to Moderate Tritanopia occurs in Age Related Macular Degeneration.

\section{References}

1. Alberti WE, Richard G, Sagerman RH (2012) AgeRelated Macular Degeneration: Current Treatment Concepts.

2. Brad Bowling (2016) Kanski's Clinical Ophthalmology E-Book: A Systematic Approach. $8^{\text {th }}$ (Edn.). 


\section{Open Access Journal of Ophthalmology}

3. Sihota, Radhika Tandon (2018) Parson's Diseases of the Eye. $22^{\text {nd }}($ Edn.).
4. Samar K Basak (2009) Clinical Ophthalmology.

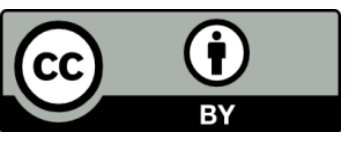

Partha Haradhan Chowdhury and Brinda Haren Shah. Effect of Colour Vision on Age Related Macular Degeneration. J Ophthalmol 2018, 3(S2): 000S2-022.
Copyright@ Partha Haradhan Chowdhury and Brinda Haren Shah. 